\title{
O Dever de Fundamentação das Decisóes Judiciais SOB O OlHar da CRÍtica HeRMENÊUTICA DO DiREITO
}

\author{
Lenio Luiz Streck* \\ Igor Raatz**
}

\begin{abstract}
1 Introdução. 2 Dimensões do dever de fundamentação. 3 Versões fracas do dever de fundamentação e o seu contraponto a partir da Crítica Hermenêutica do Direito. 3.1 Do dever de fundamentação "suficiente" ao dever de fundamentação completa: da inexorável relação entre dever de fundamentação e contraditório. 3.2 Da fundamentação como "justificação racional das escolhas do juiz para decidir" à fundamentação como explicitação da compreensão. 3.3 Precedentes não servem para desonerar o julgador de fundamentar. 4 Considerações finais. Referências.
\end{abstract}

\section{RESUMO}

Embora o dever de fundamentação das decisões judiciais constitua uma garantia contra o arbítrio de juízes e Tribunais, muitas concepções a seu respeito vêm servindo para fortalecer decisionismos e arbitrariedades. Diante desse quadro, o presente ensaio buscará oferecer, sob o olhar da Crítica Hermenêutica do Direito, um contraponto a essas versões fracas acerca do dever de fundamentação, defendendo um dever de fundamentação completa e no direito, respeitando-se, desse modo, a sua autonomia, constituindo um empreendimento democrático no qual o juiz deverá se esforçar para mostrar que a decisão em questão é a melhor (constitucionalmente adequada) para o caso concreto.

Palavras-chave: Dever de fundamentação. Autonomia do direito. Crítica Hermenêutica do Direito.

\section{INTRODUÇÃO}

Falar do dever de fundamentação das decisões judiciais em uma democracia poderia parecer algo desnecessário, afinal é condição de possibilidade para o exercício de função jurisdicional que as decisões do Poder Judiciário sejam fundamentadas. Além disso, uma pes-

* Professor Titular do Programa de Pós-Graduação em Direito da Unisinos, RS, e Unesa, RJ. Doutor e Pós-Doutor em Direito. Ex-Procurador de Justiça (MP/RS). Membro Catedrático da Academia Brasileira de Direito Constitucional - ABDCONST. Professor Emérito da EMERJ/RJ. Presidente de Honra do Instituto de Hermenêutica Jurídica (IHJ). Advogado. E-mail: <lenios@globomail.com>.

** Pós-doutorando em Direito pela UNISINOS sob a supervisão do professor Lenio Luiz Streck. Doutor e mestre em Direito pela mesma instituição. Pós-graduado em Direito Processual Civil pela ABDPC - Academia Brasileira de Direito Processual Civil. Membro da ABDPro - Associação Brasileira de Direito Processual e do IIDP - Instituto Iberoamericano de Derecho Procesal. Advogado sócio-fundador do escritório Raatz \& Anchieta Advocacia. E-mail: <igorraatz@gmail.com>. 
soa que não conhecesse a realidade dos Tribunais brasileiros poderia objetar que estaríamos discorrendo sobre uma obviedade, uma vez que a Constituição brasileira consagra o dever de fundamentação e que, portanto, ele é um elemento inexorável do processo jurisdicional democrático. Porém, aqueles que lidam com o direito no Brasil sabem que as coisas não são bem assim. Apesar de todos os esforços em fazer que o texto Constitucional seja levado a sério, inclusive com o estabelecimento minucioso de critérios legais para que seja possível afirmar a falta de fundamentação de uma decisão judicial e, portanto, a sua invalidade, um breve olhar sobre o modo como juízes e Tribunais decidem e fundamentam as suas decisões revela que, ainda, há muito a ser feito pela doutrina no sentido de constranger epistemologicamente juízes e Tribunais a respeitarem a Constituição.

Desse modo, o presente ensaio constitui um compromisso com a democracia. Isso porque não há processo jurisdicional democrático se não for respeitado o direito das partes de obter decisões fundamentadas. Em tempos difíceis, nos quais são cada vez mais comuns decisões judiciais que se limitam à mera transcrição de julgados anteriores, é imprescindível alçar o dever de fundamentação das decisões judiciais a um patamar mais elevado que o usualmente trabalhado pela doutrina brasileira. Assim, serão apresentadas e rechaçadas, à luz da Critica Hermenêutica do Direito, algumas "versões fracas" acerca do dever de fundamentação, na medida em que fundamentar uma decisão não é o mesmo desenvolver uma justificação racional capaz de encobrir a decisão, como se fosse possível cindir os dois níveis da linguagem (logos hermenêutico e logos apofântico). Com isso, defende-se que o juiz tem, ao fundamentar, o dever de empreender o maior esforço possível para mostrar que a decisão é correta (constitucionalmente adequada) e que, portanto, guarda consonância com a história institucional do direito, de modo a preservar a sua autonomia.

\section{DIMENSÕES DO DEVER DE FUNDAMENTAÇÃO}

O conteúdo do dever de fundamentação das decisões previsto no art. 93, IX, da Constituição brasileira somente pode ser precisado se explorado em uma dimensão histórica, que permita desvelar suas diferentes variações de sentido até que possamos situá-lo na perspectiva atual do Estado Democrático de Direito. ${ }^{1}$ Nesse percurso, no entanto, é possível explicitar algumas marcas envoltas àquilo que gradualmente tem perpassado a compreensão acerca do dever de fundamentação. Há, desse modo, um elemento, por assim dizer, comum às diferentes concepções acerca do dever de fundamentação, que é o fato de ser encarado como verdadeira garantia contra o arbítrio. ${ }^{2}$

Note-se que, antes mesmo do surgimento das democracias liberais, já se falava de um dever de fundamentação. Como bem afiança Mario Pisani, na Itália pré-unitária, a pragmática n. XXVIII do Rei Fernando IV de Bourbon estabelecia a obrigatoriedade de fundamentação, a fim de que os julgamentos fossem o mais possível escoimados do arbítrio, preservando-se os juízes de qualquer suspeita de parcialidade. ${ }^{3}$ Embora, nesse primeiro momento, o dever 
de fundamentação não estivesse ligado a uma concepção democrática de Estado, já era possível verificar, na fundamentação das decisões, uma arma contra o arbítrio dos juízes. Essa tendência foi gradualmente ganhando força a ponto de a obrigatoriedade da fundamentação das decisões constituir traço comum a quase todas as grandes codificações processuais do século XIX. Na tradição luso-brasileira, o dever de fundamentação esteve presente nas Ordenações Filipinas (Livro, III, LXVI, $\S 7^{\circ}$ ), as quais estabeleciam que o juiz infrator do dever de fundamentação ficaria sujeito ao pagamento de multa em favor da parte. Posteriormente, o art. 232 do Regulamento 737 de 1850 veio estabelecer que o juiz deveria motivar, com precisão, o seu julgado, preceito que acabou sendo repetido nos Códigos processuais estaduais e incorporado pelas posteriores codificações processuais brasileiras. ${ }^{4}$

À noção elementar de que o dever de fundamentação funcionava como uma espécie de ferramenta contra arbítrio judicial, foram se agregando outros elementos, como a garantia da imparcialidade do juiz, o controle da legalidade da decisão, e a possibilidade de impugnação das decisões. Há quem diga que, no bojo do Estado Democrático de Direito, a fundamentação das decisões, sem perder o caráter de freio contra eventuais arbitrariedades do julgador, passou a ser vista, também, como "elemento essencial de uma ideologia democrática da justiça." ${ }^{5}$ Nessa vereda, Michelle Taruffo afirma que a inserção do dever de fundamentação nas Constituições representa, na atual quadra da história, a transformação das funções a ela atribuída. Agrega-se à tradicional função endoprocessual da fundamentação, que visa a facilitar a impugnação e os juízos sobre ela, uma função extraprocessual. Assim, a fundamentação representaria, também, a possibilidade de controle do exercício do Poder Judiciário fora do contexto processual, por parte do povo e da opinião pública em geral, tudo dentro de uma concepção democrática do poder. ${ }^{6}$

Embora boa parte da doutrina esteja de acordo no sentido de que a fundamentação é (i) uma garantia contra o arbítrio judicial, (ii) condição para a imparcialidade do juiz, (iii) ferramenta para que se possa controlar a conformidade das decisões ao direito e que (iv) desempenha tanto funções endoprocessuais, tendentes a viabilizar a impugnação das decisões, quanto extraprocessuais, para que não somente as partes possam estabelecer constrangimentos epistemológicos às decisões proferidas pelo Poder Judiciário ${ }^{7}$, existem diferentes versões acerca de quais são os critérios para que uma decisão judicial possa ser considerada fundamentada. Muitas destas, no entanto, não guardam conformidade com o Constitucionalismo Contemporâneo e com o Estado Democrático de Direito. Diante desse quadro, no próximo item, iremos oferecer, sob a ótica da Crítica Hermenêutica do Direito, o devido contraponto a essas "versões fracas" do dever de fundamentação.

\section{VERSÕES FRACAS DO DEVER DE FUNDAMENTAÇÃO E O SEU CON- TRAPONTO A PARTIR DA CRÍTICA HERMENÊUTICA DO DIREITO}

Não é incomum encontrarmos, no âmbito dos Tribunais brasileiros, a presença de versões fracas acerca do dever de fundamentação das decisões judiciais. Trata-se de concepções 
que, em linhas gerais, restringem o dever fundamentação a um mero ônus de justificar desprovido de qualquer conteúdo. Dito de outro modo, a fundamentação transforma-se num ato meramente protocolar, um requisito que, para ser cumprido, não depende de maior esforço por parte do órgão julgador. Assim, bastaria que o juiz apresentasse qualquer justificativa à decisão judicial para considerá-la fundamentada.

Tais acepções a respeito do dever de fundamentação servem somente para mascarar um perfil nada democrático de prestação jurisdicional, em que o magistrado não precisaria pagar tributo ao próprio direito, ou seja, vale o que foi decidido, ainda que com base em argumentos morais, políticos e pragmáticos. No fim, acaba-se confundindo decisão com escolha, o que inviabiliza qualquer tentativa de controlá-la pelo próprio direito. Desse modo, tendo em vista que essas concepções se encontram arraigadas ao senso comum teórico dos juristas e, principalmente, na forma como juízes e Tribunais brasileiros fundamentam suas decisões, é tarefa da doutrina apontá-las e combatê-las.

\subsection{DO DEVER DE FUNDAMENTAÇÃO "SUFICIENTE" AO DEVER DE FUNDA- MENTAÇÃO COMPLETA: DA INEXORÁVEL RELAÇÃO ENTRE DEVER DE FUN- DAMENTAÇÃO E CONTRADITÓRIO}

Antes do advento do novo Código de Processo Civil, havia quem sustentasse uma diferença entre decisões não-fundamentadas, decisões mal fundamentadas e insuficientemente fundamentadas. ${ }^{8}$ Outra distinção que se fazia era entre decisões "suficientemente fundamentadas" nas quais deveriam constar todos os elementos que o juiz levou em conta para decidir e "decisões completas", nas quais deveria também constar "elemento fáticos e/ ou jurídicos que, segundo as partes, ou segundo uma das partes, deveriam ter sido levados em conta pelo juiz para decidir." Chegava-se a afirmar que sentenças poderiam ter fundamentação suficiente, ao passo que acórdãos proferidos pelos Tribunais locais - para viabilizar o acesso aos Tribunais Superiores, por força da exigência do prequestionamento - deveriam fundamentar de modo completo. ${ }^{10}$

Mesmo após a entrada em vigor do Código de Processo Civil de 2015, não é incomum que juízes e Tribunais sustentem a inexistência de um dever de enfrentar, de modo detido, todos os argumentos deduzidos pela parte no processo. Essa postura é somente o reflexo de um protagonismo judicial incompatível com o Estado Democrático de Direito, uma vez que neste as partes deixam de ser vistas como se estivessem sujeitas ao árbitro de um juiz que figura como "dono do processo."

Assim como o dever de fundamentação somente pode ser compreendido na sua historicidade, também o direito ao contraditório não se mostra indiferente às circunstâncias da época em que é problematizado. ${ }^{11}$ Com efeito, a visão clássica do contraditório - outrora compreendido exclusivamente como proibição de decisões inaudita altera parte - própria de 
uma estrutura procedimental dirigida a uma espécie de formação unilateral de provimentos judiciais centrada no juiz, ${ }^{12}$ cede espaço para uma noção de contraditório estruturada a partir de um direito de participação das partes no processo e na formação dos provimentos judiciais. ${ }^{13}$ Isso, obviamente, coloca em xeque velhos dogmas do processo civil, como a artificial noção de que as partes teriam a tarefa exclusiva de trazer fatos ao processo e que as questões jurídicas seriam apanágio do juiz. ${ }^{14}$

Concebido o processo como verdadeira instituição de garantia, é inconstitucional qualquer tentativa de legitimar, a partir de brocardos jurídicos que nada mais são que álibis em favor do arbítrio judicial, como é o caso do conhecido "iura novit curia", uma espécie de expectativa fiel das partes sobre a capacidade do juiz encontrar corretamente e solitariamente a melhor solução jurídica para os fatos da causa. ${ }^{15}$ Nesse sentido, mesmo sem nenhum contato com as posições teóricas que alicerçam o presente ensaio, há quem diga, na doutrina processual italiana, que deve ser afastada qualquer forma de solipsismo processual do magistrado mesmo naquilo que the é dado conhecer de ofício. ${ }^{16}$ Seja quanto aos fatos que porventura o juiz possa conhecer de ofício, ${ }^{17}$ seja quanto à chamada qualificação jurídica dos fatos da causa, é indispensável a participação das partes na formação do provimento jurisdicional.

Com essa roupagem, o contraditório pode ser visualizado a partir de um duplo enfoque: sob um aspecto positivo, significa um verdadeiro direito de influir sobre a elaboração do provimento judicial $;^{18}$ sob um aspecto negativo, constitui uma proibição às chamadas decisões surpresas, também conhecidas como juízos de terceira via, ${ }^{19}$ ou seja, como um caminho diverso daquele desenvolvido pelas partes em contraditório. ${ }^{20}$ Nas duas facetas do contraditório, o que importa revelar é a posição ocupada pelo juiz, o qual passa também a ser sujeito do contraditório em franco diálogo com as partes. ${ }^{21}$

O artigo 10 do Código de Processo Civil brasileiro é, sem dúvida, um dos mais importantes dispositivos do Código, na medida em que alberga essa nova roupagem do contraditório, inserindo o próprio juiz no debate processual, ao proibi-lo de proferir decisão, em qualquer grau de jurisdição, com base em fundamento a respeito do qual não se tenha dado às partes oportunidade de se manifestar, ainda que se trate de matéria sobre a qual deva decidir de ofício.

Desse modo, garante-se uma verdadeira proteção às partes contra o perigo de eventuais surpresas. ${ }^{22} \mathrm{~A}$ abrangência dessa proteção é bastante ampla, devendo-se entender por fundamentos da decisão todas as questões, processuais ou materiais, idôneas a repercutir no deslinde da controvérsia. ${ }^{23}$ Assim, qualquer ponto revelado ao juiz, que seja idôneo a influenciar as decisões, pode comportar, independente da natureza da questão revelada, a exigência das partes de contradizer a respeito. ${ }^{24}$ Isso abarca tanto a aplicação de normas jurídicas diversas daquelas invocadas pelas partes, ${ }^{25}$ quanto a atribuição de relevância a elementos fáticos que não foram debatidos entre as partes. ${ }^{26}$ Há, por conseguinte, uma exigência de uma prevenção de qualquer decisão surpresa. ${ }^{27}$ 
O aspecto ativo do contraditório, visualizado como direito de influência, guarda inexorável relação com o princípio da fundamentação das decisões. $O$ contraditório, nesse viés, compreende poderes que correspondem a uma possibilidade de participar ativamente do desenvolvimento do processo e, portanto, de influir sobre os provimentos do juiz. ${ }^{28} \mathrm{O}$ contraditório, com efeito, não é só informação, mas também participação em toda a atividade processual, de modo que essa participação seja efetivamente capaz de influir no resultado do processo. ${ }^{29}$

A compreensão do princípio do contraditório como verdadeiro direito de influência somente tem relevância se contrastada com o princípio da fundamentação das decisões. Nisso reside um dos pontos mais sensíveis do Novo Código, que, na contramão da prática judiciária brasileira, incorporou, no seu artigo 489, $\$ 1^{\circ}$, uma série de critérios para balizar o conceito de decisão fundamentada, dentre eles, a previsão do inciso IV do mencionado dispositivo, segundo o qual não se considera fundamentada qualquer decisão judicial que "não enfrentar todos os argumentos deduzidos no processo capazes de, em tese, infirmar a conclusão adotada pelo julgador". 30

Cabe lembrar, utilizando as palavras de Ovídio Baptista da Silva, que "o direito ao contraditório não se esgota na faculdade de ser ouvido e produzir alegações e provas." ${ }_{1}$ As partes têm, portanto, "o direito a uma resposta,"32 que compreende "o direito de ver as alegações e provas produzidas também pelo sucumbente examinadas e, além disso, rejeitadas com argumentos racionalmente convincentes." 33

Sob essa perspectiva, cabe ressaltar que a fundamentação é, também, uma espécie de resposta ao princípio do contraditório. Dessa forma, o juiz pode até considerar errados os argumentos das partes, mas deve, para resguardar o contraditório como direito de influência, levá-las em consideração, fazendo menção expressa às teses propostas pelos sujeitos processuais. Trata-se do dever de atenção às alegações, intrinsecamente coligado ao dever de fundamentação das decisões estatais e ao correlato direito dos cidadãos de verem as suas linhas argumentativas consideradas pelo juiz (Recht auf Berücksichtigung). ${ }^{34}$ Por sinal, há mais de uma década, o Supremo Tribunal Federal sustentou que a "pretensão à tutela jurídica envolve não só o direito de manifestação e o direito de informação sobre o objeto do processo, mas também o direito de ver seus argumentos contemplados pelo órgão julgador." ${ }^{35}$ Embora esse mesmo Supremo seja também exemplo de vários outros casos em que o dever de fundamentação (completa) não é respeitado, isso não permite que se possa reduzir as exigências impostas pelo dever de fundamentação. Afinal, a fundamentação da decisão se revela como sendo o principal mecanismo para que as partes possam verificar se suas atividades defensivas foram efetivamente respeitadas. ${ }^{36}$ Somente haverá fundamentação "completa" quando ela abranger as razões pelas quais o juiz recusou os argumentos deduzidos pelas partes. ${ }^{37}$

Portanto, o direito das partes em obter decisões fundamentadas é dependente do respeito ao contraditório, este compreendido como garantia da possibilidade da influência (e 
efetiva participação) das partes na formação da resposta judicial, questão que se refletirá na fundamentação da decisão, que deve explicitar o iter percorrido no processo, ${ }^{38} \mathrm{com}$ o enfrentamento dos argumentos deduzidos pelas partes. Sem esse mínimo necessário, qualquer decisão judicial será considerada carente de fundamentação e incorrerá em violação aos artigos 10 e 489, $\S 1^{\circ}$, do Código de Processo Civil brasileiro.

\subsection{DA FUNDAMENTAÇÃO COMO "JUSTIFICAÇÃO RACIONAL DAS ESCOLHAS DO JUIZ PARA DECIDIR” À FUNDAMENTAÇÃO COMO EXPLICITAÇÃO DA COMPREENSÃO}

Muitos autores que defendem um dever de fundamentação completa, ainda assim, possuem uma visão limitada a respeito do tema na medida em que, embora busquem estabelecer critérios para que uma decisão esteja devidamente fundamentada, partem do pressuposto de que seja possível cindir fundamentação e decisão. Desse modo, fundamentar uma decisão consistiria simplesmente na construção de uma justificativa racional para a decisão judicial, tomada posteriormente ao decidido mediante argumentos muitas vezes capazes de encobrir as razões subjacentes à decisão.

Nesse sentido, por exemplo, Taruffo levanta a seguinte questão: "formular uma decisão e expor as razões através das quais ela deve ser considerada pelos outros como uma boa decisão são atividades diversas." ${ }^{39}$ Desse modo, a fim de confirmar a ausência de uma necessária correspondência entre decisão e fundamentação, afirma que uma decisão tomada intuitivamente, ou ainda de modo irracional, poderá ser justificada ex post com argumentos racionalmente convincentes, da mesma forma que uma decisão tomada por meio de um raciocínio irracional poderá ser justificada em modo racionalmente inadequado ou não ser justificada de fato. ${ }^{40}$ Com efeito, a fundamentação deveria ser estruturada de modo a justificar a decisão. Não se trataria de um controle do que o juiz pensou, mas da racionalidade das razões que ele aduziu para justificar o que decidiu: "o controle sobre a motivação não é um controle sobre a validade e fundamentação das decisões feitas, mas sobre a validade e fundamentação das razões pelas quais o juiz se serve para tornar aceitável 'aos outros' a sua decisão." ${ }^{11}$ Essa justificação teria um conteúdo mínimo consistente no enunciado das escolhas do juiz em relação à individualização das normas aplicáveis e às consequências jurídicas delas decorrentes, os nexos de implicação e coerência entre os enunciados fáticos e jurídicos e, por fim, a justificação dos enunciados tomada racionalmente em face do ordenamento jurídico. ${ }^{42}$ Dessa forma, fundamentar a decisão, em termos processuais, equivaleria a uma justificativa tomada em momento posterior a partir de elementos jurídico-racionais. Dito de outro modo, a justificação estaria em um segundo nível em relação à decisão e àquilo que efetivamente fundamentou o decidido. Em uma perspectiva hermenêutica, diríamos que, segundo essa perspectiva, o problema da fundamentação das decisões estaria limitado ao logos apofântico e a uma possibilidade de fazer enunciações descoladas do como hermenêutico. ${ }^{43}$ 
Em uma tentativa de sofisticar ainda mais essa versão que também denominaremos de fraca acerca do dever de fundamentação, alguns setores da doutrina processual vêm utilizando-se de conceitos oriundos da filosofia, mais precisamente a diferença entre contexto da descoberta e contexto da justificação. Nesse sentido, Marinoni, Mitidiero e Arenhart referem que pouco importa o contexto da decisão (context of dicovery), na medida em que interessa para a aferição da sua validade somente o contexto da justificativa (context of justification), ou seja, as razões que foram invocadas para a sua justificação. ${ }^{44}$

É importante esclarecer que suposta dicotomia entre fundamentação e justificação, que remete a uma suposta cisão entre o contexto da descoberta e o contexto da justificação, remonta a certos paradigmas filosóficos, como é o caso da filosofia analítica, do empirismo lógico e do positivismo dos filósofos do círculo de Viena, podendo ser citado o exemplo de Herbert Feigl, que via no contexto da justificação "uma reconstrução lógica das estruturas conceituais e dos testes das teorias científicas." ${ }^{45}$ Referida cisão, no final das contas, representa uma espécie de primazia do contexto da justificação, ignorando-se a questão da dobra da linguagem tão cara à hermenêutica filosófica e à filosofia hermenêutica. Trata-se, portanto, de uma postura que somente poderia ser recepcionada à luz de uma "hermenêutica metodológica", cuja atividade e validade se encontra reduzida ao nível do logos apofântico, em detrimento do ainda-não-dito. Ela delimita o interpretar ao mundo do dito, ignorando sua outra margem, o não-dito, como se houvesse uma conversão dos sentidos do plano hermenêutico para o apofântico. ${ }^{46}$

Cabe lembrar que o como apofântico trata daquilo que é expressável em locuções ou enunciados. No entanto, esse expressar sempre chega depois, ele é antecedido por uma pré-compreensão interpretante elementar das coisas do meio, ao nível do ser-aí. ${ }^{47}$ Partindo dessas bases, a filosofia hermenêutica ofereceu um novo olhar sobre a dicotomia contexto da descoberta e contexto da justificação. O contexto da descoberta não constitui em si uma operação lógica, de modo que as proposições aí produzidas sob o império da presunção de uma totalidade lógica terão que revelar sua consciência no contexto de justificação. O contexto da justificação é uma parada metodológica. É então que a antecipação de proposições é ou não confirmada em sua coerência interna. Esta é a situação hermenêutica produzida pelo caminho da analítica existencial: nela o feixe de pressuposições - antecipações confirmadas - representa o momento de consciência do "método", a consciência da boa circularidade. Conforme Stein, o contexto de justificação em Ser e Tempo é coincidente com a situação hermenêutica. A partir daí, o caminho andado da provisória analítica do quotidiano - significando análise do objeto com uso implícito do método - se revela retrospectivamente válido, e a consciência do método permite refazer, já com a totalidade antecipada, em uma operação de antecipação de sentido, confirmada e justificada, a analítica existencial sob o signo da antecipação exitosa. Na condição produzida pelo "encurtamento hermenêutico", em que está excluída a fundação (justificação), quer por uma proposição cosmológica, quer por uma proposição teológica, as proposições da analítica existencial só podem ser produzidas com sentido, por 
meio da boa circularidade da antecipação de sentido. Isso quer dizer que a totalidade é presumida (no contexto da descoberta) e explicitada no momento da situação hermenêutica (no contexto da justificação). Desse modo, explicitação do método coincide com explicitação do objeto de toda analítica, ou em outras palavras: a justificação do modo de proceder coincide com o resultado da própria exposição do objeto. ${ }^{48}$

Portanto, há um grave equívoco filosófico, incompatível com a Crítica Hermenêutica do Direito, em aceitar uma cisão entre o momento decisório e o ato de fundamentação. Não que Michelle Taruffo, por exemplo, ingenuamente acredite que a fundamentação venha depois do que foi decidido, porém ele parece considerar impossível um controle da fundamentação e, por isso, acredita que bastaria ao julgador formular a decisão e depois expor as razões pelas quais ela deveria ser considerada pelos outros como uma boa decisão. E, com isso, ele acaba aceitando que o verdadeiro fundamento, aquele que acompanhou a decisão, seja mascarado por uma justificação posterior fundada em critérios jurídico-racionais, ou seja, coerentes e universalizáveis.

Há muito, pela Crítica Hermenêutica do Direito, tem-se advertido que "o julgador não decide para depois buscar a fundamentação; ao contrário, ele só decide porque já encontrou o fundamento." ${ }^{49} \mathrm{O}$ fundamento, no caso, é condição de possibilidade para a decisão tomada. Isso porque há um sentido que é antecipado ao julgador, do qual "a decisão é parte inexorável (dependente) do fundamento." ${ }^{50}$ É claro que o julgador, em um segundo momento, poderá aprimorar o fundamento, utilizando-se, por exemplo, da doutrina e da jurisprudência, e deverá, ainda, submeter seus prejuízos a respeito da decisão e do seu fundamento em causa, ao crivo dos argumentos deduzidos no processo (e também do que é colocado pela doutrina e pela jurisprudência), dizendo expressamente porque repeliu os argumentos utilizados pelas partes, levando-se em consideração que a fundamentação é o locus de resposta ao direito de influência decorrente do contraditório. ${ }^{51}$ Fazendo isso, o julgador estará colocando em xeque o próprio fundamento que o levou a decidir, de modo que, nesse processo decisório, poderá haver diversos fundamentos e decisões até que se chegue à resposta adequada ao caso concreto, a partir da (boa) circularidade hermenêutica.

Nessa senda, afigura-se inconcebível admitir que o juiz possa justificar a decisão de modo a mascarar os verdadeiros fundamentos que são inexoráveis à decisão. A falsa ideia de que a decisão se traduz na possibilidade de o juiz fazer escolhas, acaba servindo de álibi para que a fundamentação não venha explicitada na decisão. Por isso que fundamentar não significa encobrir o fundamento a partir de uma simples "justificação racional”, mas, sim, deixá-lo vir à tona. Cumpre com o dever de fundamentação o julgador quando explicita o compreendido. No entanto, "explicitar o compreendido não é colocar uma capa de sentido ao compreendido." ${ }^{52}$

Aqui entra em jogo o problema de se admitir inúmeras respostas para cada caso. Ora, a aceitação desse pressuposto - que, diga-se de passagem, é incompatível com o dever de 
integridade previsto no art. 926 do Código de Processo Civil - legitima que o juiz primeiro decida e, posteriormente, busque argumentos racionais para justificar a sua decisão, como se a fundamentação fosse apenas uma capa de sentido. Com efeito, permite-se que seja encoberto aquilo que serviu de fundamento para a decisão, de modo que fundamentar passa a significar uma justificativa (dentre as tantas possíveis) para a decisão. Desse modo, deixa-se de exigir do julgador que, para decidir, coloque em xeque seus pré-juízos diante da Constituição, da lei, da doutrina e da jurisprudência. Dito de outro modo, basta que o julgador encontre argumentos dotados de racionalidade para que sua decisão se considere fundamentada.

Portanto, o dever de fundamentação não pode ser encarado como um simples dever de justificação. $\mathrm{O}$ art. 93, IX, da Constituição Federal somente será respeitado quando o julgador se desincumbir do ônus de demonstrar que sua decisão é correta, que está fundada em prejuízos legítimos e que sua subjetividade não se sobrepôs ao direito a sua história institucional, levando-se em consideração o contexto circunstancial dos fatos definidor do caso concreto. Com efeito, não se encontrará cumprido o dever de fundamentação somente com a menção a critérios lógicos, sendo indispensável colocar o sentido ventilado na decisão no contexto da história institucional do direito. ${ }^{53}$

\subsection{PRECEDENTES NÃO SERVEM PARA DESONERAR O JULGADOR DE FUNDA- MENTAR}

Não é de hoje que, sob o olhar da Crítica Hermenêutica do Direito, tem-se denunciado os riscos decorrentes da utilização de mecanismos vinculantes no direito brasileiro, principalmente no que diz respeito à fundamentação das decisões judiciais. Há muito, súmulas, ementas e outros expedientes vêm sendo utilizados como enunciados assertóricos vocacionados a oferecer, de antemão, respostas antes das perguntas. E, para piorar, criou-se um modo de operar por parte de juízes e Tribunais mediante o qual estes se veem desonerados de fundamentar suas decisões, optando pelo caminho da "simplicidade": basta invocar julgados anteriores e, assim, o órgão julgador não precisará fazer menção a um dispositivo legal sequer na sua decisão. ${ }^{54}$ Simples, não?

Essa forma de encarar o dever de fundamentação goza de um visível déficit democrático. Trata-se de um expediente rasteiro que atua em dois sentidos: de um lado, importa num incomensurável reforço de poder em favor dos Tribunais Superiores, na medida em que juízes e Tribunais do andar de baixo transformam-se em verdadeiros "boca do precedente"; por outro, reduz o nível de qualidade das fundamentações das decisões judiciais, pois juízes de diferentes Tribunais são seduzidos pelo caminho facilitado de justificar suas decisões a partir de "precedentes de prateleira" que são "comprados" na exata medida em que servirem para subsidiar o discurso de justificação da decisão. ${ }^{55}$ Sob essa ótica, o "precedente" acaba servindo para confirmar a decisão (confirmatio in bias) atendendo às preferências do julgador, em uma espécie de "self service insano", tudo ao "gosto do intérprete."56 
Note-se que, no common law, a aplicação de precedentes é analisada pelo juiz levando em consideração os fatos e partindo deles.$^{57}$ Trata-se de algo muito distante daquilo que - de modo equivocado - acontece no direito brasileiro, em que uma suposta "armação normativa" construída a partir de conceitos sem coisas balizaria a seleção dos fatos relevantes da controvérsia. ${ }^{58}$ Desse modo, pode-se dizer que, no common law, a chave do judicial reasoning está na decisão sobre semelhança e diferença entre os casos e, portanto, antes de tudo, na escolha dos aspectos, dos elementos, das características e dos perfis a assumir como termos de referência de semelhança e diferença. ${ }^{59}$ Portanto, quando os fatos relevantes usados pela Corte para proferir sua decisão no caso precedente são suficientemente semelhantes àqueles do caso apresentado para julgamento, estará justificada a aplicação daquele como vinculante, desde que a regra de direito aplicada naquele caso não tenha sido modificada pelo legislador. ${ }^{60}$ Portanto, é o caso futuro que determinada se o caso precedente será vinculante ou não. ${ }^{61}$

Desse modo, os incisos V e VI do art. 489 do CPC devem ser lidos na sua melhor luz, para que não sirvam de álibi retórico em favor de decisões que se limitam a enunciar supostos "precedentes" como fundamentação. Desse modo, ainda que a decisão invoque algum mecanismo vinculante como base para a sua fundamentação, isso não significa que o juiz esteja desonerado de oferecer a melhor resposta para o caso à luz da Constituição e da lei. A invocação do "precedente", como bem aponta Juraci Mourão Lopes Filho em excelente obra sobre o tema, não pode se dar de modo reducionista, desconsiderando-se os amplos aspectos hermenêuticos envolvidos na solução anterior e no novo caso em que está inserido. ${ }^{62}$ Isso impõe que, ao ser utilizado um precedente no bojo da fundamentação da decisão judicial, deve ser realizada uma reconstrução da história institucional do direito, com a perquirição do DNA dos casos pretéritos mencionados, os quais devem ser devidamente relacionados e contrastados com o caso decidendo.

Por outro lado, a previsão do inciso VI do artigo 489 do CPC, ao estabelecer que não se considera fundamentada qualquer decisão judicial que "deixar de seguir enunciado de súmula, jurisprudência ou precedente invocado pela parte, sem demonstrar a existência de distinção no caso em julgamento ou a superação do entendimento", ${ }^{63}$ não significa uma obediência cega aos mecanismos vinculantes previstos no art. 927 do CPC. Na verdade, o inciso VI do art. 489 consiste em uma espécie de desdobramento do dever de fundamentação completa, pois prevê que o juiz não poderá deixar de enfrentar argumentos oferecidos pelas partes com base em "mecanismos vinculantes". Até porque o art. 927 do CPC diz que referidos mecanismos devem ser observados, e não que devem sempre ser seguidos, como se fossem uma espécie de "enunciação suprema acerca do sentido do direito" superior às leis e à própria Constituição. Eles devem ser explorados, portanto, a partir do dever de coerência e integridade previsto no art. 926 do CPC, o que irá repercutir diretamente nos contornos do dever de fundamentação. 


\section{CONSIDERAÇÕES FINAIS}

É bem verdade que, ao longo do tempo, o dever de fundamentação sofreu transformações, sem, contudo, perder seu caráter essencial de garantia contra o arbítrio judicial. Porém, ele deve ser contextualizado a partir dos paradigmas do Constitucionalismo Contemporâneo e do Estado Democrático de Direito, nos quais não mais se admite que o Direito seja predado por discursos morais, políticos e pragmáticos.

Desse modo, não se admite, na atual quadra da história, que o dever de fundamentação continue sendo encarado como um mero ônus de justificação racional das escolhas do juiz. Decisão não é escolha, mas, sim, um ato de responsabilidade política da magistratura. Com muito esforço, o Direito conquistou sua autonomia, de modo que não faz sentido fragilizá-la admitindo que o juiz cumpre com o dever de fundamentação tão somente apresentando justificativas racionais para a sua decisão. As decisões judiciais devem ser fundamentadas no direito.

Juízes e Tribunais não têm o dever de proferir qualquer decisão. Devem se empenhar para proferir a decisão correta para o caso (adequada à Constituição); e não basta qualquer fundamentação. As partes, em qualquer processo jurisdicional, têm o direito fundamental a que as decisões sejam uma espécie de empreendimento democrático, em que os seus argumentos sejam levados a sério e que a autonomia do direito seja respeitada, esforçando-se o órgão julgador para mostrar que a decisão em questão é a melhor, de acordo com o direito, para o caso concreto.

\section{REFERÊNCIAS}

ANZON, Adele. Il valore de precedente nel giudizio sulle leggi. Milano: Giuffrè, 1995.

BUONCRISTIANI, Dino. Il nuovo art. 101, comma $2^{\circ}$, C.P.C. sul contraddittorio e sui rapporti tra parti e giudice. Rivista di diritto processuale, Padova, v. 65, n. 2, p. 399-415, 2010.

CABRAL, Antônio do Passo. Il Principio del contraddittorio come diritto d'influenza e dovere di dibattito. Rivista di diritto processuale. Padova: CEDAM, 2005.

CALMON DE PASSOS, José Joaquim. A formação do convencimento do magistrado e a garantia constitucional da fundamentação das decisões In: TUBENCHLAK, James (Coord.). Livro de Estudos Jurídicos. Rio de Janeiro: Instituto de Estudos Jurídicos, 1991. v. 3.

CAPPELLETTI, Mauro. Spunti in tema di contradditorio. In: STUDI in memoria di Salvatore Satta. Padova: Cedam, 1982. Volume primo.

CARNEIRO, Athos Gusmão. Sentença mal fundamentada e sentença não-fundamentada: conceitos: nulidades. Revista AJURIS, Porto Alegre, n. 65, nov. 1995.

COLE, Charles D. Stare decisis na cultura juridica dos estados unidos: o sistema de precedente vinculante do common law. Revista dos Tribunais, São Paulo, v. 87, n. 752, p. 11-21, jun. 1998. 
COMOGLIO, Luigi Paolo. Terza via e processo giusto. Rivista di diritto processuale, $\mathrm{Pa}-$ dova, n. 2, 2006.

. Il "giusto processo" civile in italia e in europa. Revista de Processo, São Paulo, v. 29, n. 116, p. 97-158, 2004.

DENTI, Vittorio. Questioni rilevabili d'ufficio e contraddittorio. Rivista di diritto processuale, Padova, v. 23, p. 217-231, 1968.

FEIGL, Herbert. A visão "ortodoxa" de teorias: comentários para defesa assim como para crítica. Scientiae Studia, São Paulo, v. 2, n. 2, p. 265-277, 2004.

GOODHART, Arthur L. The ratio Decidendi of a Case. In: JURISPRUDENCE in actione: a pelader's Anthology. New York: Baker, Voorhis \& Co. Inc., 1953.

GOTTHEIL, Julio. Common law y civil law: el common law y nuestro sistema juridico. Buenos Aires: Abeledo-Perrot, 1960.

GRADI, Marco. Il principio del contraddittorio e la nullità dela sentenza dela "terza via". Rivista di diritto processuale, Padova, v. 65, n. 4, p. 826-848, 2010.

GRINOVER, Ada Pellegrini. O controle do raciocínio judicial pelos tribunais superiores brasileiros. AJURIS: Revista da Associação dos Juízes do Rio Grande do Sul, Porto Alegre, v. 17, n. 50, p. 5-20, nov. 1990.

GRODIN, Jean. Introdução à hermenêutica filosófica. Tradução de Benno Dischinger. São Leopolo: Editora Unisinos, 1999.

LOPES FILHO, Juraci Mourão. Os precedentes judiciais no constitucionalismo brasileiro contemporâneo. 2. ed. Salvador: Editora JusPodivm, 2016.

LIEBMAN, Enrico Tullio. Do arbítrio à razão: reflexões sobre a motivação da sentença. Revista de Processo, São Paulo, v. 29, n. 8, p. 79-81, jan./mar. 1983.

MARINONI, Luiz Guilherme; ARENHART, Sérgio; MITIDIERO, Daniel. Novo curso de processo civil: tutela dos direitos mediante procedimento comum. São Paulo: Revista dos Tribunais, 2015. v. 2.

MONTESANO, Luigi. La garanzia costituzionale del contraddittorio e i giudizi civili di "terza via”. Rivista Di Diritto Processuale, Padova, v. 55, n. 4, p. 929-947, out. 2000.

MOREIRA, José Carlos Barbosa. Súmulas, jurisprudência, precedente: uma escalada e seus riscos. São Paulo: Saraiva, 2007.

. A motivação das decisões judiciais como garantia inerente ao Estado de Direito. 2. ed. São Paulo: Saraiva, 1988.

. Os Princípios do direito processual civil na Constituição de 1988. In: Temas de direito processual. São Paulo: Saraiva, 1993. 
NORMAND, Jacques. I poteri del giudice e delle parti quanto al fondamento delle pretense controverse. Rivista di dirritto procesuale, Padova, v. 43, parte II, 1988.

PICARDI, Nicola. Audiatur et Altera Pars: as matrizes histórico-culturais do contraditório. In: OLIVEIRA, Carlos Alberto Alvaro de. Jurisdição e processo. Rio de Janeiro: Forense, 2008. PISANI, Mario. Notas para a história da motivação no processo penal. Revista de direito penal, Rio de Janeiro, n. 1, jan./mar. 1971.

REICHENBACH, Hans. Elements of symbolic logic. New York: The Macmillan, 1948.

ROHDEN, Luiz. Interfaces da hermenêutica: método, ética e literatura. Caxias do Sul: Educs, 2008.

SILVA, Ovídio A. Bapstista da. Fundamentação das sentenças como garantia constitucional. Revista do Instituto de Hermenêutica Jurídica, Porto Alegre, v. 1, n. 4, p. 323-352, 2006. STEIN, Ernildo. Aproximações sobre hermenêutica. Porto Alegre: EDIPUCRS, 2010.

. Seis estudos sobre ser e tempo: comemoração dos sessenta anos de Ser e Tempo de Heidegger. 2. ed. Petrópolis: Vozes, 1990.

STRECK, Lenio Luiz. Verdade e consenso. 5. ed. São Paulo: Saraiva, 2014.

. Hermenêutica jurídico e $(\mathrm{m})$ crise: uma exploração hermenêutica da construção do Direito. 10. ed. Porto Alegre: Livraria do Advogado, 2011.

. Hermenêutica, constituição e processo, ou de "como discricionariedade não combina com democracia": o contraponto da resposta correta. Constituição e processo: a contribuição do processo ao constitucionalismo democrático brasileiro. Coordenação de Marcelo Andrade Cattoni de Oliveira e Felipe Daniel Amorim Machado. Belo Horizonte: Del Rey, 2009.

- Jurisdição constitucional e hermenêutica: uma nova crítica do direito. Porto Alegre: Livraria do Advogado, 2002.

TARUFFO, Michelle. Il controllo di razionalità della decisione fra logica, retorica e dialetica. Revista de processo, São Paulo, v. 32, n. 143. jan. 2007.

. Il Significato constituzionale dell'obblligo di motivazione. In: GRINOVER, Ada Pelegrini; DINAMARCO, Cândido Rangel; WATANABE, Kazuo (Coord.). Participação e processo. São Paulo: Revista dos Tribunais, 1988.

. La motivazine della sentenza civile. Padova: CEDAM, 1975.

TARZIA, Giuseppe. O contraditório no processo executivo. Revista de processo, São Paulo, v. 28, out./dez. 1982.

THEODORO JÚNIOR, Humberto et al. Novo CPC: fundamentos e sistematização. 2. ed. Rio de Janeiro: Forense, 2015. 
THEODORO JÚNIOR, Humberto; NUNES, Dierle José Coelho. Uma dimensão que urge reconhecer ao contraditório no direito brasileiro: sua aplicação como garantia de influência, de não surpresa e de aproveitamento da atividade processual. Revista de Processo, São Paulo, v. 34, n. 168, p. 107-141, fev. 2009.

THOMPSON, Donald. Il precedente giudiziario nel diritto constituzionale inglese. In: LA DOTTRINA del precedente nella giurisprudenza della corte costituzionale. A cura di Giuseppino Treves. Torino: Unione Tipográfico - Editrice Torinense, 1971.

TROCKER, Nicolò. Processo civile e costituzione; problemi di diritto tedesco e italiano. Milano: Giuffrè, 1974.

WAMBIER, Teresa Arruda Alvim. Omissão judicial e embargos de declaração. São Paulo: Revista dos Tribunais, 2005.

1 Conforme Barbosa Moreira há muito advertia, "tem variado inclusive no tempo e no espaço o próprio entendimento de 'decisão motivada', ou, em outras palavras, a extensão dos requisitos que se hão de satisfazer para que se tenha por cumprido o dever de fundamentar os pronunciamentos judiciais" MOREIRA, José Carlos Barbosa. A motivação das decisões judiciais como garantia inerente ao Estado de Direito: temas de direito processual. 2. ed. São Paulo: Saraiva, 1988. p. 86.

2 LIEBMAN, Enrico Tullio. Do arbítrio à razão: reflexões sobre a motivação da sentença. Revista de Processo, São Paulo, v. 29, n. 8, p. 79-81, jan./mar. 1983.p. 80.

3 Essa concepção está presente na "pragmática no . XXVIII", do Rei Fernando IV de Bourbon, a qual, segundo Mario Pisani, estabeleceu, pela primeira vez na Itália pré-unitária, a obrigatoriedade de motivação: "Encare Sua Majestade que os julgamentos devem ser o mais possível escoimados do arbítrio, e bem assim devem ser os Juízes preservados de qualquer suspeita de parcialidade; por isso, e para isso, as decisões devem fundar-se não já na pura autoridade dos Doutores, que, infelizmente, com as suas opiniões, têm alterado o direito, ou têm-no tornado incerto ou arbitrário, mas nas leis, expressas do reino, ou mesmo comuns. Se não houver lei expressa para o caso de que se trata, devendo-se então recorrer à interpretação ou à extensão da lei, quer o Rei que isso seja feito pelo Juiz de tal modo que as duas premissas do raciocínio sejam sempre fundadas em leis expressas e literais. E quando o caso for totalmente novo, ou inteiramente duvidoso, de sorte que não possa haver decisão dentro da lei, nem ao amparo da lei, quer o Rei que lhe seja dito caso encaminhado, e se aguarde o seu Soberano Pronunciamento" PISANI, Mario. Notas para a história da motivação no processo penal. Revista de direito penal, Rio de Janeiro, n. 1, jan./mar. 1971. p. 68.

4 MOREIRA, José Carlos Barbosa. A motivação das decisões judiciais como garantia inerente ao Estado de Direito: temas de direito processual. São Paulo: Saraiva, 1988. p. 85.

5 TARUFFO, Michelle. Il Significato constituzionale dell' obblligo di motivazione. In: GRINOVER, Ada Pelegrini; DINAMARCO, Cândido Rangel; WATANABE, Kazuo (Coord.). Participação e processo. São Paulo: Revista dos Tribunais, 1988. p. 38.

6 TARUFFO, Michelle. La motivazine della sentenza civile. Padova: CEDAM, 1975. p. 237.

7 Nesse último sentido, ver STRECK, Lenio Luiz. Hermenêutica, constituição e processo, ou de "como discricionariedade não combina com democracia": o contraponto da resposta correta. Constituição e processo: a contribuição do processo ao constitucionalismo democrático brasileiro / coordenação de Marcelo Andrade Cattoni de Oliveira e Felipe Daniel Amorim Machado. Belo Horizonte: Del Rey, 2009.

8 Nesse sentido, Athos Gusmão Carneiro dizia que, na hipótese de decisão malfundamentada, não há que se falar em nulidade, mas, sim, em utilização do meio de impugnação contra ela cabível. Assim, quando o juiz se equivoca ao apreciar as questões de fato e/ou de direito que lhe foram submetidas, a decisão está, em princípio, errada, mas será válida. O mesmo, para ele, não corre com a decisão sucintamente fundamentada, que, embora possa pecar pela má-técnica, não são nulas. Entretanto, a sentença com fundamentação sucinta não deverá 
ser confundida com a sentença deficiente, incompleta em sua fundamentação CARNEIRO, Athos Gusmão. Sentença mal fundamentada e sentença não-fundamentada: conceitos: nulidades. Revista AJURIS, Porto Alegre, n. 65, nov. 1995. p. 8-9.

9 WAMBIER, Teresa Arruda Alvim. Omissão judicial e embargos de declaração. São Paulo: Revista dos Tribunais, 2005. p. 352.

10 WAMBIER, Teresa Arruda Alvim. Omissão judicial e embargos de declaração. São Paulo: Revista dos Tribunais, 2005. p. 390

11 Sobre o tema, ver PICARDI, Nicola. Audiatur et Altera Pars: as matrizes histórico-culturais do contraditório. In: OLIVEIRA, Carlos Alberto Alvaro de. Jurisdição e processo. Rio de Janeiro: Forense, 2008.

12 THEODORO JÚNIOR, Humberto; NUNES, Dierle José Coelho. Uma dimensão que urge reconhecer ao contraditório no direito brasileiro: sua aplicação como garantia de influência, de não surpresa e de aproveitamento da atividade processual. Revista de Processo, São Paulo, v. 34, n. 168, p. 107-141, fev. 2009. p. 117. Essa perspectiva, como bem mostra Nicola Picardi, deve-se à passagem do medievo para modernidade, do iudicium para o processus, que traduz uma mudança no modo de conceber o fenômeno processual. Nesse sentido, com o jusnaturalismo moderno, já se evidencia uma linha de decadência do princípio do contraditório. Abandonada a metodologia dialética de investigação, o contraditório tendia então a se resolver em uma mecânica contraposição de teses e, em última análise, em uma prova de forças. Iniciava, assim, o processo de formalização e de transcrição do diálogo em termos de direitos e obrigações. À concepção clássica de verdade "provável" sucedia-se a confiança na existência de uma verdade objetiva, absoluta, pré-constituída. Outro problema era, depois, o de identificar - com base em postulados epistemológicos, respectivamente, empirísticos ou racionalísticos - tal verdade com a verdade "material" ou com a "formal". Seja como for, tinha-se que tais verdades poderiam ser alcançadas mesmo sem o contraditório (...) O novo ordo, sob a direção do juiz, apresenta, de maneira definitiva, um caráter "assimétrico", na medida em que fundamentalmente apoiado sob a autoridade, a hierarquia e a lógica burocrática. De resto, já Leibniz havia redimensionado a função do advogado, sustentando que o juiz é, de ofício, o advogado geral das partes (PICARDI, Nicola. Audiatur et Altera Pars: as matrizes histórico-culturais do contraditório. In: OLIVEIRA, Carlos Alberto Alvaro de. Jurisdição e processo. Rio de Janeiro: Forense, 2008. p. 136-137).

13 CAPPELLETTI, Mauro. Spunti in tema di contradditorio. In: STUDI in memoria di Salvatore Satta. Padova: Cedam, 1982. Volume primo. p. 210.

14 NORMAND, Jacques. I poteri del giudice e delle parti quanto al fondamento delle pretense controverse. Rivista di dirritto procesuale, Padova, v. 43, parte II, p. 724-725, 1988.

15 BUONCRISTIANI, Dino. Il nuovo art. 101, comma 2 $2^{\circ}$, C.P.C. sul contraddittorio e sui rapporti tra parti e giudice. Rivista di diritto processuale, Padova, v. 65, n. 2, p. 399-415, 2010. p. 408.

16 GRADI, Marco. Il principio del contraddittorio e la nullità dela sentenza dela "terza via". Rivista di diritto processuale, Padova, v. 65, n. 4, p. 826-848, 2010. p. 826.

17 O juiz pode, portanto, participar da construção do edifício do fato, salvo quando se trate de fatos constitutivos individualizadores do direito (porque do contrário estaria o juiz a estabelecer o objeto do processo) ou fatos impeditivos, modificativos e extintivos objeto de exceções em sentido estrito, reservados à parte (nesse caso, a vontade da parte em servir-se da eficácia jurídica daquele fato é elemento constitutivo da exceção). Ocorre, porém, que apresente o conhecimento do fato ao contraditório das partes e que estas últimas tenham a possibilidade de livremente se defender. (BUONCRISTIANI, Dino. Il nuovo art. 101, comma $2^{\circ}$, C.P.C. sul contraddittorio e sui rapporti tra parti e giudice. Rivista di diritto processuale, Padova, v. 65, n. 2, p. 399-415, 2010. p. 406).

18 COMOGLIO, Luigi Paolo. Il giusto processo civile in Italia e in Europa. Revista de processo, São Paulo, n. 116, p. 132, ago. 2004.

19 GRADI, Marco. Il principio del contraddittorio e la nullità dela sentenza dela "terza via". Rivista di diritto processuale, Padova, v. 65, n. 4, p. 826-848, 2010. p. 827.

20 COMOGLIO, Luigi Paolo. Terza via e processo giusto. Rivista di diritto processuale, Padova, n. 2, p. 758, 2006.

21 Conforme Giuseppe Tarzia, "a participação no 'diálogo' não reclama somente que tenha havido aviso da audiência e conhecimento dos pronunciamentos emitidos pelo juiz, e, portanto, a sua comunicação, quando não tenham sido proferidos na audiência. A extensão ao juiz do princípio do contraditório, pelo menos na sua 
versão mais moderna, comporta a ideia de obrigação em relação ao próprio juiz - e, para aquilo que nos concerne, especificamente para o juiz da execução - de submeter à discussão prévia das partes as questões releváveis de ofício, sobre as quais crê necessário dever pronunciar-se (por exemplo, as questões relativas à competência, à jurisdição e outras das quais se falou acima), atuando, dessa forma, a 'tuteladas partes contra o perigo das surpresas', que parece ser essenciais em um processo efetivamente dominado pelo princípio que agora se está examinando". TARZIA, Giuseppe. O contraditório no processo executivo. Revista de processo, São Paulo, v. 28, p. 74-75, out./dez. 1982. Nesse sentido, também, MONTESANO, Luigi. La garanzia costituzionale del contraddittorio e i giudizi civili di "terza via". Rivista Di Diritto Processuale, Padova, v. 55, n. 4, p. 929-947, out. 2000. p. 931.

22 TROCKER, Nicolò. Processo civile e costituzione: problemi di diritto tedesco e italiano. Milano: Giuffrè, 1974. p. 499.

23 DENTI, Vittorio. Questioni rilevabili d’ufficio e contraddittorio. Rivista di diritto processuale, Padova, v. 23, p. 217-231, 1968. p. 225.

24 GRADI, Marco. Il principio del contraddittorio e la nullità dela sentenza dela "terza via". Rivista di diritto processuale, Padova, v. 65 , n. 4, p. 826-848, 2010. p. 837-838.

25 Como pode acontecer no caso no qual se modifique o título da responsabilidade de contratual para extracontratual, ou vice-versa, ou quando se entenda modificar, a respeito da opinião das partes, a natureza do contrato objeto do processo, terminando por aplicar disposições diversas com resultados e êxitos, enquanto em abstrato previsíveis, em concreto não previstas pelas partes. GRADI, Marco. Il principio del contraddittorio e la nullità dela sentenza dela "terza via". Rivista di diritto processuale, Padova, v. 65, n. 4, p. 826-848, 2010. p. 836.

26 Como poderia ocorrer no caso no qual, em uma controvérsia referente ao objeto da responsabilidade, o órgão judicante decida a causa com referência ao nexo causal frente a uma contestação do dano inerente ao elemento exclusivamente subjetivo. GRADI, Marco. Il principio del contraddittorio e la nullità dela sentenza dela "terza via”. Rivista di diritto processuale, Padova, v. 65, n. 4, p. 826-848, 2010. p. 838).

27 COMOGLIO, Luigi Paolo. Il "giusto processo" civile in italia e in europa. Revista de Processo, São Paulo, v. 29, n. 116, p. 97-158, 2004. p. 132.

28 TARZIA, Giuseppe. Il Contraddittorio nel Processo Esecutivo. In: ESECUZIONE forzata e procedure concorsuali. Milano: Cedam, 1994. p. 60

29 MOREIRA, José Carlos Barbosa. Os Princípios do direito processual civil na constituição de 1988. In:

Temas de direito processual. São Paulo: Saraiva, 1993. p. 243

30 THEODORO JÚNIOR, Humberto et al. Novo CPC: fundamentos e sistematização. 2. ed. Rio de Janeiro: Forense, 2015.

31 SILVA, Ovídio A. Bapstista da. Fundamentação das sentenças como garantia constitucional. Revista do Instituto de Hermenêutica Jurídica, Porto Alegre, v. 1, n. 4, p. 323-352, 2006. p. 340.

32 SILVA, Ovídio A. Bapstista da. Fundamentação das sentenças como garantia constitucional. Revista do Instituto de Hermenêutica Jurídica, Porto Alegre, v. 1, n. 4, p. 323-352, 2006. p. 340.

33 SILVA, Ovídio A. Bapstista da. Fundamentação das sentenças como garantia constitucional. Revista do Instituto de Hermenêutica Jurídica, Porto Alegre, v. 1, n. 4, p. 323-352, 2006. p. 340.

34 CABRAL, Antônio do Passo. Il Principio del contraddittorio come diritto d'influenza e dovere di dibattito. Rivista di diritto processuale, Padova, p. 456-57, 2005.

35 BRASIL. STF, Segunda Turma, ROMS no 24.536-4, Rel. Ministro Gilmar Mendes, julgado em 2/12/2003. D. J. de 05.03.2004. Para um aprofundamemnto do tema, ver STRECK, Lenio Luiz. Verdade e consenso. 5. ed. São Paulo: Saraiva, 2014. p. 611-620.

36 TROCKER, Nicolò. Processo civile e constituzione. Processo civile e costituzione; problemi di diritto tedesco e italiano. Milano: Giuffrè, 1974. p. 460.

37 SILVA, Ovídio A. Bapstista da. Fundamentação das sentenças como garantia constitucional. Revista do Instituto de Hermenêutica Jurídica, Porto Alegre, v. 1, n. 4, p. 323-352, 2006. p. 340.

38 STRECK, Lenio Luiz. Hermenêutica, constituição e processo, ou de "como discricionariedade não combina com democracia": o contraponto da resposta correta. Constituição e processo: a contribuição do processo ao constitucionalismo democrático brasileiro / coordenação de Marcelo Andrade Cattoni de Oliveira e Felipe Daniel Amorim Machado. Belo Horizonte: Del Rey, 2009. p. 17-18.

39 TARUFFO, Michelle. Il controllo di razionalità della decisione fra logica, retorica e dialetica. Revista de 
processo, São Paulo, v. 32, n. 143. jan. 2007. p. 76.

40 TARUFFO, Michelle. Il controllo di razionalità della decisione fra logica, retorica e dialetica. Revista de processo, São Paulo, v. 32, n. 143. jan. 2007. p. 76.

41 TARUFFO, Michelle. Il controllo di razionalità della decisione fra logica, retorica e dialetica. Revista de processo, São Paulo, v. 32, n. 143. jan. 2007. p. 75.

42 TARUFFO, Michelle. La motivazine della sentenza civile. Padova: CEDAM, 1975. p. 467. GRINOVER, Ada Pellegrini. O controle do raciocínio judicial pelos tribunais superiores brasileiros. AJURIS: Revista da Associação dos Juízes do Rio Grande do Sul, Porto Alegre, v. 17, n. 50, p. 5-20, nov. 1990. p. 8-9.

43 Como bem assinala Stein, com base em Heidegger, "a linguagem traz em si um duplo elemento, um elemento lógico formal que manifesta as coisas na linguagem, e o elemento prático de nossa experiência de mundo anterior à linguagem, mas que não se expressa senão via linguagem, e este elemento é o como e o logos hermenêutico. Heidegger irá designar esses dois como, um deles o como hermenêutico e o outro o como apofântico. $\mathrm{O}$ enquanto hermenêutico ou o como hermenêutico, é o como do mundo, e o outro, o como apofântico é o como do discurso. O como hermenêutico é o como do nosso mundo prático em que nós já sempre compreendemos as coisas e, por isso, podemos falar delas através de enunciados assertóricos predicativos. A racionalidade, portanto, se constitui sempre de uma certa maneira ambígua. Seja-nos permitido usar esta palavra: Há uma ambiguidade fundamental no homem e por haver esta ambiguidade fundamental é que estamos condenados à hermenêutica. A compreensão e a interpretação são formas deficientes de acesso lógico aos objetos e de acesso lógico ao mundo, mas talvez sejam formas sábias. Em todo caso quem tem consciência disso é apenas a filosofia". STEIN, Ernildo. Aproximações sobre hermenêutica. Porto Alegre: EDIPUCRS, 2010. p. 21-22. Como será visto mais adiante, o problema da fundamentação das decisões judiciais não se resolve no nível apofântico da linguagem.

44 MARINONI, Luiz Guilherme; ARENHART, Sérgio; MITIDIERO, Daniel. Novo curso de processo civil: tutela dos direitos mediante procedimento comum. São Paulo: Revista dos Tribunais, 2015. v. 2. p. 411-412.

45 FEIGL, Herbert. A visão "ortodoxa" de teorias: comentários para defesa assim como para crítica. Scientiae Studia, São Paulo, v. 2, n. 2, p. 265-77, 2004. A distinção tem origem no pensamento de Hans Reichenbach, que distingue o modo de o pensador encontra o seu teorema e o modo de apresentá-lo ao púbico. REICHENBACH, Hans. Elements of symbolic logic. New York: The Macmillan, 1948.

46 ROHDEN, Luiz. Interfaces da hermenêutica: método, ética e literatura. Caxias do Sul: Educs, 2008. p. 42.

47 GRODIN, Jean. Introdução à hermenêutica filosófica. Tradução de Benno Dischinger. São Leopolo: Editora Unisinos, 1999.

48 STEIN, Ernildo. Seis estudos sobre ser e tempo: comemoração dos sessenta anos de Ser e Tempo de Heidegger. 2. ed. Petrópolis: Vozes, 1990. p. 59-61.

49 STRECK, Lenio Luiz. Jurisdição constitucional e hermenêutica: uma nova crítica do direito. Porto Alegre: Livraria do Advogado, 2002. p. 180.

50 STRECK, Lenio Luiz. Jurisdição constitucional e hermenêutica: uma nova crítica do direito. Porto Alegre: Livraria do Advogado, 2002. p. 180.

51 CALMON DE PASSOS, José Joaquim. A formação do convencimento do magistrado e a garantia constitucional da fundamentação das decisões In: TUBENCHLAK, James (Coord.). Livro de Estudos Jurídicos. Rio de Janeiro: Instituto de Estudos Jurídicos, 1991. v. 3. p. 12.

52 STRECK, Lenio Luiz. Hermenêutica jurídico e $(\mathrm{m})$ crise: uma exploração hermenêutica da construção do Direito. 10. ed. Porto Alegre: Livraria do Advogado, 2011. p. 398. Conforme Streck: "Quando sustento o dever de accountability, não estou simplesmente dizendo que a fundamentação 'resolve' o problema decorrente, por exemplo, do livre convencimento, da livre apreciação da prova ou da admissão lato sensu da discricionariedade. Por favor, não é isso que estou dizendo. Accountability, nos moldes em que proponho, quer dizer fundamentação da fundamentação. Isso quer dizer que nem de longe o problema da exigência de fundamentação se resolve no nível apofântico. Ora, com tudo o que já escrevi, eu não seria ingênuo em pensar que o 'dever de fundamentar as decisões' resolver(ia) o problema da decisão...! Um vetor de racionalidade de segundo nível - lógico-argumentativo - não pode se substituir ao vetor de racionalidade de primeiro nível, que é a compreensão. Nela, na compreensão, reside a 'razão hermenêutica', para usar a expressão de Ernst Schnädelbach. Afinal, por que razão Gadamer diria que 'interpretar é explicitar o compreendido'? Note-se: explicitar o compreendido não é colocar uma capa de sentido ao compreendido. Esse é o espaço da epistemologia da hermenêutica. Não nos esqueçamos, 
aqui, do dilema das teorias cognitivistas-teleológicas: não é possível atravessar o abismo do conhecimento - que 'separa' o homem das coisas - construindo uma ponte pela qual ele já passou. Não se pode fazer uma leitura rasa do art. 93, IX, da CF. A exigência de fundamentação não se resolve com 'capas argumentativas', ou seja, o juiz não deve 'explicar' aquilo que o 'convenceu'...deve, sim, explicitar os motivos de sua compreensão, oferecendo uma justificação (fundamentação) de sua interpretação, na perspectiva de demonstrar como a interpretação oferecida por ele é a melhor para aquele caso (mais adequada à Constituição ou, em termos dworkinianos, correta), em um contexto de unidade, integridade e coerência com relação ao Direito da Comunidade Política". STRECK, Lenio Luiz. Hermenêutica jurídico e $(\mathrm{m})$ crise: uma exploração hermenêutica da construção do Direito. 10. ed. Porto Alegre: Livraria do Advogado, 2011. p. 398-399.

53 STRECK, Lenio Luiz. Hermenêutica jurídica e $(\mathrm{m})$ crise: uma exploração hermenêutica da construção do Direito. 10. ed. Porto Alegre: Livraria do Advogado, 2011. p. 289.

54 Há muito, lembra José Carlos Barbosa Moreira que, "em nosso país, quem examinar os acórdãos proferidos, inclusive pelos tribunais superiores, verificará que, na grande maioria, a fundamentação dá singular realce à existência de decisões anteriores que hajam resolvido as questões de direito atinentes à espécie sub iudice. Não raro, a motivação reduz-se à enumeração de precedentes: o tribunal dispensa-se de analisar as regras legais e os princípios jurídicos pertinentes - operação que estaria obrigado, a bem da verdade, nos termos do art. 458, $\mathrm{n}^{\mathrm{o}}$ II, do Código de Processo Civil, aplicável aos acórdãos nos termos do art. 158 - e substitui o seu próprio raciocínio pela mera invocação de julgados anteriores”. MOREIRA, José Carlos Barbosa. Súmulas, jurisprudência, precedente: uma escalada e seus riscos. São Paulo: Saraiva, 2007. Temas de direito processual (nona série). p. 300.

55 STRECK, Lenio Luiz. Hermenêutica jurídica e $(\mathrm{m})$ crise: uma exploração hermenêutica da construção do direito. 11. ed. Porto Alegre: Livraria do Advogado, 2014. p. 165-175.

56 THEODORO JÚNIOR, Humberto et al. Novo CPC: fundamentos e sistematização. 2. ed. Rio de Janeiro: Forense, 2015. p. 353.

57 GOODHART, Arthur L. The ratio Decidendi of a Case. In.: JURISPRUDENCE in actione: a pelader's Anthology. New York: Baker, Voorhis \& Co. Inc., 1953. p. 222.

58 Trata-se de um modo peculiar de conceber a aplicação do direito no âmbito da civl law, que tem sido objeto de crítica há mais de meio século, como se vê em GOTTHEIL, Julio. Common law y civil law; el common law y nuestro sistema juridico. Buenos Aires: Abeledo-Perrot, 1960. p. 100.

59 ANZON, Adele. Il valore de precedente nel giudizio sulle leggi. Milano: Giuffrè, 1995. p. 57.

60 COLE, Charles D. Stare decisis na cultura juridica dos estados unidos. o sistema de precedente vinculante do common law. Revista dos Tribunais, São Paulo, v. 752, p. 15, 1998.

61 THOMPSON, Donald. Il precedente giudiziario nel diritto constituzionale inglese. In: LA DOTTRINA del precedente nella giurisprudenza della corte costituzionale. A cura di Giuseppino Treves. Torino: Unione Tipográfico - Editrice Torinense, 1971. p. 187.

62 LOPES FILHO, Juraci Mourão. Os precedentes judiciais no constitucionalismo brasileiro contemporâneo. 2. ed. Salvador: Editora JusPodivm, 2016. p. 27.

63 THEODORO JÚNIOR, Humberto et al. Novo CPC: fundamentos e sistematização. 2. ed. Rio de Janeiro: Forense, 2015. 


\title{
THE DUTY TO PRESENT THE REASONING OF JUDICIAL DECISIONS UNDER HERMENEUTICAL CRITIC OF THE LAW
}

\begin{abstract}
Although the duty to present judicial reasoning constitutes a guarantee against the discretion of judges and courts, many conceptions about it have been serving to reinforce "decisionism" and arbitrariness. In view of the situation, the present essay seeks to offer, under the perspective of the Hermeneutical Critic of the Law, a counterpoint to these weak versions of the duty to present judicial reasoning, defending a duty to present a complete judicial based on the law, respecting, thereby, its autonomy, constituting a democratic thus respecting, as such, judicial autonomy and building a democratic enterprise in which the judge must make an effort to show that the decision in question is the best (and constitutionally adequate) for the concrete case.
\end{abstract}

Keywords: Duty to present judicial reasoning. Autonomy of the Law. Hermeneutical Critic of the Law.

Submetido: 3 abr. 2017

Aprovado: 26 abr. 2017 